\title{
Tecnologias sociais: interface com as políticas públicas e o Serviço Social
}

\section{Social technologies: interface with public policy and Social Work}

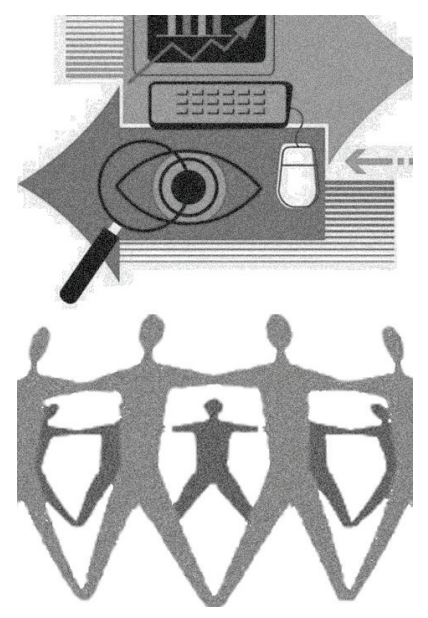

\author{
Ana Lúcia Suárez Maciel* \\ Rosa Maria Castilhos Fernandes*
}

Resumo: O artigo aborda a temática das Tecnologias Sociais — TS, tendo como parâmetro a experiência das autoras como articuladoras de uma rede de organizações que atuam com TS no estado do Rio Grande do Sul. Para tanto, apresenta uma breve contextualização histórica e conceitual das TS, relacionando-as com a atual política de ciência e tecnologia vigente no Brasil e, também, sinalizando-as como uma demanda para a atuação e investigação dos assistentes sociais, tendo em vista a potencialidade das TS se constituírem como uma política pública e de inovação social.

Palavras-chave: Tecnologia social. Políticas públicas. Serviço Social.

\begin{abstract}
The article talks about the Social Technologies (TS), using as the experience of the authors articulate how a network of organizations working with TS in the state of Rio Grande do Sul It presents a brief historical background and the conceptual TS, relating them to the current policy of science and technology law in Brazil and also signaling to them as a demand for action and research of social workers, in view of the potential of TS to be constituted as a public policy and social innovation.
\end{abstract}

Keywords: Social technology. Public policy. Social Work.

* Assistente social, mestre e doutora em Serviço Social pelo PPGSS-PUCRS - Porto Alegre/RS, Brasil, professora e pesquisadora do PPGSS-PUC-RS, vice-presidente da Diretoria Executiva Fundação Irmão José Otão _-FIJO.E-mail: ana.suarez@pucrs.br.

** Assistente Social, mestre e doutora em Serviço Social pelo PPGSS, coordenadora de Desenvolvimento Social da Fundação Irmão José Otão — Porto Alegre/RS, Brasil — FIJO. E-mail: rmariacf@uol.com.br ou rosac@fijo.org.br. 


\section{Introduzindo a temática das tecnologias sociais}

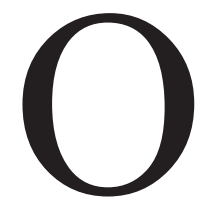

cenário mundial, caracterizado pela crise econômica de grandes potências capitalistas e protagonizado pelas mudanças advindas da esfera produtiva, pela radicalização dos ideários neoliberais e pela reestruturação do Estado, vem impactando nas diferentes dimensões da vida social e afetando transversalmente a divisão do trabalho, as relações entre as classes e a organização da produção e distribuição de bens e serviços (Iamamoto, 2008). Associa-se a esse contexto a realidade brasileira marcada pela desigualdade social que coloca o Brasil em evidência no cenário mundial, tanto pelas disparidades regionais internas quanto pelos processos de distribuição de renda que se caracterizam pela acumulação de uma minoria em detrimento das necessidades da maioria da população brasileira. São esses processos de exclusão social em que vive grande parte da população que sinalizam o quanto ainda precisamos percorrer para formularmos e instituirmos políticas públicas que incidam em uma totalidade mais abrangente.

Contraditoriamente, no Brasil, o progresso científico e tecnológico tem se ampliado e, com isso, mostrado a sua eficácia em criar novos bens e serviços. Nesse processo não vem sendo atendida a necessidade básica de ampla camada da população e tampouco questionado os impactos sociais, ambientais o que, muitas vezes, resultam no aumento da degradação do meio ambiente e da exclusão social. Assim, se pode afirmar que há um descompasso significativo entre desenvolvimento científico-tecnológico e desenvolvimento social. Parte desse descompasso tem sua gênese no atual padrão de desenvolvimento científico e tecnológico do país que vem sendo operado sob o argumento de que a relação entre ciência, tecnologia e inclusão social se dá de maneira concomitante e automática.

No entanto, o que se percebe é que o "caminho que vai da realização de um descobrimento ou progresso científico em algum laboratório até que a sociedade se beneficie dele é longo, difícil e exige a atuação contínua do Estado" (ITS, 2005, p. 3). Portanto, a discussão sobre as relações entre ciência, tecnologia, inovação e sociedade são complexas e heterogêneas, principalmente quando se trata de construir alternativas e políticas públicas que sejam capazes 
de promover melhorias significativas nas condições de vida da classe trabalhadora, aproximando o "saber do fazer, os problemas de suas soluções, em sintonia com a diversidade socioeconômica e ambiental das regiões brasileiras" (ITS, 2005, p. 3).

Nesta perspectiva, as tecnologias sociais têm emergido no cenário brasileiro como um movimento de "baixo para cima", que se caracteriza pela capacidade criativa e organizativa de segmentos da população em gerar alternativas para suprir as suas necessidades e/ou demandas sociais. Não se constituem, ainda, em políticas públicas, mas vêm obtendo um reconhecimento crescente no que se refere à sua capacidade de promover um novo modelo de produção da ciência e da aplicação da tecnologia em prol do desenvolvimento social.

$\mathrm{Na}$ esteira desse movimento, encontram-se algumas organizações que vêm apoiando tais iniciativas e que se encontram vinculadas às instituições de ensino superior e à sociedade civil. No seu conjunto, essas iniciativas conformam uma estratégia emergente para fazer frente aos processos excludentes, vislumbradas como instrumento para inclusão social e de acesso ao conhecimento.

Nesse sentido, este artigo se propõe a evidenciar a importância de inserir na pauta da categoria dos assistentes sociais esta temática que tem sido motivo de luta social e mobilização da sociedade civil organizada em defesa da TS como política pública, logo, com uma identidade que se aproxima do atual projeto profissional. As reflexões propostas neste texto contextualizam aspectos históricos e conceituais sobre as TS e a sua sistematização, ainda que sinteticamente expressa na indicação de algumas experiências que vêm sendo desenvolvidas em diferentes regiões do país, com o intuito de exemplificá-las. $\mathrm{Na}$ sequência, são levantados aspectos que contribuem com a reflexão crítica sobre a política de ciência e tecnologia brasileira e se faz algumas considerações que justificam a interlocução das TS com as políticas públicas, o que se constitui o principal desafio dos atores que atuam junto a esse movimento emergente. Por último, faz-se uma aproximação com o Serviço Social, sobretudo para introduzir este debate na agenda profissional, pois não há como negar a relação da temática com o compromisso dos assistentes sociais com a defesa das políticas públicas e com um projeto ético-político profissional voltado para a justiça social e para a garantia de direitos. 


\section{Aspectos históricos e conceituais das tecnologias sociais}

Inicialmente, é preciso referir que tratar sobre TS significa abordar processos que, concomitantemente, se inserem na agenda contemporânea do conhecimento e na mais antiga das intenções de superação da pobreza na história da humanidade. Significa tratar sobre as ações concretas e os resultados alcançados por meio do trabalho de pessoas que resolveram problemas inspirados pela sabedoria e mobilização popular e, em algumas situações, com o apoio de pesquisadores.

A TS vem sendo discutida no Brasil, nesta primeira década do século XXI, por diferentes atores sociais, tais como organizações da sociedade civil, universidades, integrantes do governo, trabalhadores, entre outros, e vem se constituindo uma das respostas possíveis para o atendimento das demandas sociais. Há entre esses atores uma preocupação com a crescente exclusão social, a precarização e a informalização do trabalho, a violação dos direitos humanos e, também, a crescente compreensão acerca dos limites da atual política de ciência e tecnologia no país.

Para compreender o conceito de TS partimos do significado da palavra tecnologia como sendo um conjunto de conhecimentos, processos e métodos empregados em diversos ramos. De forma genérica, tecnologia pode ser definida como uma atividade socialmente organizada e baseada em planos e de caráter prático (Baumgarten, 2006). Ao empregarmos o complemento social, entendemos que esse conjunto de conhecimentos, processos e métodos deva estar à disposição da sociedade, visando efetivação e expansão de direitos, assim como o desenvolvimento social. A adesão do termo social à tecnologia traz a dimensão socioambiental e a construção de processos democráticos e o objetivo de solucionar as necessidades da população, para a esfera do desenvolvimento tecnológico (ITS, 2007).

A tecnologia, assim como toda produção humana "deve ser pensada no contexto das relações sociais e dentro de seu desenvolvimento histórico" (Baumgarten, 2006, p. 288). As transformações societárias que culminaram no capitalismo, a hegemonia imposta pela ciência sobre outras formas de explicação do mundo, o reconhecimento de suas virtualidades e racionalidades e o desenvolvimento tecnológico que tornou possível são alguns dos aspectos sóciohistóricos a ser considerados (Baumgarten, 2006). Quando se trata da hegemo- 
nia e da institucionalização da política científica e tecnológica nos países capitalistas, é possível referir que as mesmas decorrem das transformações operadas no modo de produção desta sociedade.

Seguindo a lógica da dimensão histórica, ao nos reportarmos as TS encontramos na literatura que trata sobre o marco analítico conceitual da vertente de sua concepção, o que se chamou no Ocidente de tecnologia apropriada (TA), cujo berço seria reconhecido na Índia do final do século XIX. Naquela época, o pensamento dos reformadores estava voltado para a reabilitação e o desenvolvimento de tecnologias tradicionais, praticadas nas próprias aldeias e que pudessem se contrapor ao domínio britânico. Gandhi (entre 1924 e 1927) dedicou-se a construção de programas, visando a popularização da fiação manual realizada em uma roca de fiar e que até hoje é reconhecida como o primeiro equipamento tecnologicamente apropriado, o chamado charkha. Esse foi um movimento de luta contra a injustiça social e o sistema de castas que se perpetuava na Índia, despertando naquela população "a consciência política sobre a necessidade de auto-organização do povo e da renovação da indústria nativa hindu, o que pode ser avaliado pela significativa frase por ele cunhada: produção pelas massas, não pela produção em massas" (Dagnino, 2004, p. 19).

Ainda considerando o marco histórico conceitual, é importante referir que a TS, apesar de sofrer forte influência dos movimentos da TA, acaba se diferenciando da expressão que ganha força desde o final do século XX.

A TS se diferencia, sobretudo, por superar a concepção de transferência de tecnologia ainda presente na TA ao incluir, como elemento central das práticas que designa a construção do processo democrático participativo e a ênfase na dimensão pedagógica. Assim, as populações antes consideradas como "demandantes" de tecnologias passam a ser atores diretos no processo de construção de desenvolvimento tecnológico, sem se limitar mais à "recepção de tecnologias". (ITS, 2007, p. 28)

Alguns fundamentos são pertinentes à concepção de TS: a transformação social, a participação direta da população, o sentido de inclusão social, a melhoria das condições de vida, a sustentabilidade socioambiental e econômica, a inovação, a capacidade de atender necessidades sociais específicas, a organização e a sistematização da tecnologia, o diálogo entre diferentes saberes - acadêmicos e populares —, a acessibilidade e a apropriação das tecnologias, a 
difusão e a ação educativa, a construção da cidadania e de processos democráticos, entre outros, que são sustentados por valores de justiça social, democracia e direitos humanos. Com estes tópicos, pode-se afirmar que um dos objetivos da TS é justamente reverter a tendência vigente da tecnologia capitalista convencional que tem como pressuposto reforçar a dualidade desse sistema, "submetendo os trabalhadores aos detentores dos meios de produção e países subdesenvolvidos a países desenvolvidos, perpetuando e ampliando as assimetrias de poder dentro das relações sociais e políticas" (Dagnino, 2009, p. 18). Em contraposição a esse modelo a TS reúne características, tais como:

Ser adaptada a pequenos produtores e consumidores; não promover o tipo de controle capitalista, segmentar, hierarquizar e dominar os trabalhadores; ser orientada para satisfação das necessidades humanas (produção de valores de uso - "o mundo não é uma mercadoria, tal como nos informa o lema do Fórum Social Mundial"); incentivar o potencial e a criatividade do produtor direto e dos usuários; ser capaz de viabilizar economicamente empreendimentos como cooperativas populares, assentamentos de reforma agrária, a agricultura familiar e pequenas empresas. (Novaes e Dias, 2009, p. 18-19)

Tais características supracitadas demonstram o quanto a TS está voltada para a "produção coletiva e não mercadológica" e, também, da mesma forma, está "mais imbricada a realidades locais, de modo que pudesse gerar respostas mais adequadas aos problemas colocados em um determinado contexto" (Novaes e Dias, 2009, p. 19). Também seguindo a linha conceitual sobre TS é importante frisar que as TS sempre consideram as especificidades das realidades locais e estão diretamente relacionadas aos processos de organização coletiva e democrática e, portanto, acabam representando soluções para a superação de diferentes situações problemáticas de vulnerabilidade e exclusão social, incidindo assim na melhoria das condições de vida daqueles atores envolvidos com a TS.

Considerando os movimentos e iniciativas dos atores sociais que vem discutindo e disseminando as TS destacamos a criação da Rede de Tecnologias Sociais - RTS no Brasil, onde foi gerado o conceito de TS da seguinte forma: “(...) produtos, técnicas ou metodologias reaplicáveis, desenvolvidas na interação com a comunidade e que representem efetivas soluções de transformação social" (RTS, 2007, p. 28). A RTS é uma rede que reúne 786 organizações de 
todo país e do exterior, entre organizações não governamentais, centros de pesquisa, cooperativas, empresas, escolas de ensino médio, fundações e institutos, sindicatos, universidades e órgãos de governo nos níveis federal, estadual e municipal.

O objetivo da RTS é ampliar a difusão e a reaplicação de tecnologias sociais possibilitando a inclusão social, a geração de trabalho e renda e a promoção do desenvolvimento local sustentável. São experiências que permitem a reaplicação e já são usadas em diversas localidades do Brasil e em outros países. Ações como essas, que incentivam a interação das comunidades locais e promovem soluções na vida das pessoas, são apoiadas pela referida rede. As instituições que fazem parte da Rede, até o momento têm um propósito comum: entender as TS como importantes ferramentas para o desenvolvimento humano e a formação de uma sociedade mais justa. Também pactuam desta concepção a Fundação Banco do Brasil (FBB), entidade que hoje protagoniza um conjunto de iniciativas que promovem a disseminação das TS em diferentes regiões do país e o próprio Ministério da Ciência e Tecnologia (MCT). Este último reconhece que o objetivo da TS é o de contribuir para a redução do quadro de pobreza, analfabetismo, fome e exclusão social por meio da utilização das tecnologias sociais. Como exemplos das TS que vêm sendo disseminadas no país podemos citar:

- Barraginhas: contenção de águas da chuva: como um telhado, o solo coleta a água das chuvas e a concentra em forma de enxurradas. Ao contê-las com barraginhas sucessivas e dispersas na propriedade, são barrados danos como erosões, assoreamentos, poluentes e outros. A tecnologia social barraginhas se aplica à região do cerrado, semiárido e outras onde predominam solos porosos.

- Banco de Palmas: é um banco comunitário organizado pela Associação dos Moradores do Conjunto Palmeira, localizado em Fortaleza (CE). Trata-se de um sistema econômico que conta com uma linha de microcrédito alternativo (para produtores e consumidores), instrumentos de incentivo ao consumo local (cartão de crédito e moeda social circulante) e alternativa de comercialização (feiras e lojas solidárias), promovendo localmente geração de emprego e renda para diversas pessoas. 
- Encauchados de vegetais da Amazônia: a tecnologia social combina técnicas ancestrais de saber indígena, no manuseio do látex nativo, com as atuais tecnologias usadas nas indústrias para a transformação da borracha em artefatos. O projeto em implantação nas comunidades extrativistas dos estados do Pará, Acre, Rondônia e Amazonas, com populações indígenas (Kaxi-nawá, Shanenawa, Apurinã e Kaxarari), com seringueiros, em reservas extrativistas e projetos de assentamento, está proporcionando condições para o desenvolvimento local, de forma sustentável.

- Central Justa Trama: trata-se de agricultores familiares, coletores de sementes, fiadoras, tecedores e costureiras que formam a Justa Trama, marca da Cadeia Ecológica do Algodão Solidário. Esta experiência de TS reúne mais de setecentos trabalhadores e trabalhadoras em sete estados do país e tem capacidade para produzir até 40 mil peças por ano. Os empreendimentos cobrem todos os elos da indústria têxtil — do plantio do algodão à roupa (produzida na Cooperativa Justa Trama em Porto Alegre-RS).

- Rede Industrial de Confecção Solidária (RICS) é formada por grupos de trabalhadoras gaúchas que integram a rede de empreendimentos autogestionários da RICS; esta TS foi consolidada a partir de um convênio entre a Oscip Guayi e o Grupo Hospitalar Conceição de Porto Alegre, para costurar a linha hospitalar e, atualmente, se desenvolve por sete grupos com perspectiva de reaplicação para outras localidades.

- Produção Agroecológica Integrada e Sustentável (PAIS): é um modelo circular de agricultura orgânica que têm sido difundido pela Fundação Banco do Brasil desde 2005. No Brasil, existem 6 mil unidades implantadas ou em fase de implantação. Devido aos resultados alcançados com a tecnologia, que promove a segurança alimentar aliada à formação de crianças e jovens, como garantia da subsistência de agricultores e preservação ambiental, o PAIS é um dos projetos brasileiros selecionados pelo Ministério das Relações Exteriores (MRE) para ser aplicado em El Salvador, que será beneficiado com uma missão de cooperação humanitária brasileira em 2010 (FBB, 2008). Tal articulação sinaliza as possibilidades de reaplicação das TS entre os países da América Latina. 
Poderíamos citar ainda outras TS que são desenvolvidas e já foram reaplicadas, ${ }^{1}$ mas a intenção aqui é ilustrar com esses exemplos o quanto é possível por meio das TS promover a inclusão social de trabalhadores, de zonas rurais ou urbanas, de atores sociais de diferentes ciclos de vida, de famílias que se encontram em situação de vulnerabilidade e risco social que de forma coletiva vivenciam experiências que incidem não somente nas suas condições de vida, transformando a si mesmos, mas transformando o cenário socioeconômico da comunidade em que vivem e do país.

É diante desse cenário que a defesa das TS como política pública se apresenta como uma estratégia promissora para superar os limites do atual modelo e padrão de ciência e tecnologia vigente no país, bem como a resposta mais sintonizada com as demandas da sociedade por um modelo de desenvolvimento social que tenha centralidade no processo de inclusão social e como atores principais a própria sociedade. Atualmente, as TS apresentam significativo avanço no país, seja pelas organizações que se instituíram na última década, visando a disseminação dos conceitos e práticas, seja pela capacidade de criação das mesmas, por meio das iniciativas populares e da sua reaplicação em todo o território nacional.

Portanto, o futuro do desenvolvimento das TS em grande parte encontra-se relacionado com a capacidade de alterar a atual política de ciência e tecnologia no país, assim com a capacidade de torná-la uma política pública, tendo em vista que as experiências existentes no território nacional apontam para a sua efetividade no que se refere à capacidade de gerar respostas inovadoras para a resolução de velhas demandas sociais e, com isso, impacto social nas comunidades que se beneficiam com tais tecnologias.

\section{Tecnologias sociais: uma pauta emergente para as políticas públicas}

Recentemente no Fórum Social Mundial de 2010, ${ }^{2}$ um grupo de representantes da sociedade civil, das universidades, de conselheiros do controle

1. Sobre as TS sistematizadas, sugerimos acessar os sites: <www.rts.org.br; www.fbb.org.br; www.its. org.br>.

2. O Fórum Social Mundial aconteceu no final de janeiro de 2010 na cidade de Porto Alegre. O referido grupo foi mobilizado pelas autoras deste artigo que atuam em uma Fundação, que se encontra vinculada 
social, da RTS, do MCT, entre outros, mobilizados em torno da temática "Ciência, tecnologia e inovação" promoveram um debate que culminou na elaboração de um documento que tem como premissa principal a defesa das TS como política pública. Nesta parte do texto se pretende socializar o conteúdo que fundamentou o debate e que tem como alicerce teórico os estudos de Fonseca $(2009)^{3}$ e as análises preliminares que a participação nos eventos que antecedem à $4^{\text {a }}$ Conferência Nacional de Ciência, Tecnologia e Inovação tem nos propiciado sistematizar até o momento da redação deste texto.

Tratar sobre a temática das TS, sobretudo quando se defende sua instituição como política pública, requer o estabelecimento da sua relação com a política de ciência e tecnologia (PCT) que tem uma trajetória recente no país, sendo institucionalizada pelo Estado na década de 1950, a partir do protagonismo dos cientistas. Desde a sua criação, identifica-se que essa política tem uma centralidade significativa no trabalho desses cientistas, sendo construída nos moldes e feições da atividade científica. Isso é o que, na teoria, acabou sendo chamado de movimento modelo institucional ofertista linear, dentro da PCT. Ofertista porque o Estado oferta recursos para os cientistas implementarem as pesquisas que eles desejam e, também porque não dirige o fomento de C\&T para determinada direção. A ideia do linear é importante para essa concepção de TS e para a ideia de impacto da C\&T no desenvolvimento no país. O que está por trás disso é a concepção de uma cadeia linear de inovação, onde se espera que o investimento em pesquisa básica resulte em pesquisa aplicada, que vai resultar em tecnologia, que vai resultar em desenvolvimento econômico e que, consequentemente, vai resultar em desenvolvimento social (Maciel e Fernandes, 2010).

A crença nessa cadeia e na sua respectiva difusão é que vai legitimar o papel dos cientistas e continua legitimando, até hoje, a centralização do comando dessa política na mão dos cientistas. A ideia é que investindo em tecnologia, com uma concepção de neutralidade da ciência, se tem um caminho de desen-

\footnotetext{
à RTS como articuladora da Rede no estado do Rio Grande do Sul e que teve na sua agenda de trabalho, no ano de 2010, a promoção do debate sobre TS nos movimentos locais, estaduais e regionais que culminaram com a $4^{a}$ Conferência Nacional de Ciência e Tecnologia que ocorreu no mês de maio de 2010 em Brasília.

3. Referimo-nos a tese de doutorado intitulada Política científica e tecnológica para o desenvolvimento social: uma análise do caso brasileiro", defendida na Unicamp em 2009, sob orientação do prof. dr. Renato Dagnino.
} 
volvimento predeterminado, sendo que nessa perspectiva o cientista tem uma preponderância muito grande na formulação, implementação e avaliação da política de ciência e tecnologia como um todo.

Como vem sendo formulada a política de C\&T no Brasil? Os editais são os canais de acesso ao fomento e dependem das avaliações dos comitês ad hoc de cientistas que vão elaborar os editais, dar o direcionamento, fazer a avaliação dos projetos que são submetidos e definir os projetos a serem aprovados. A avaliação é feita pelos próprios pares de cientistas, ou seja, são os próprios cientistas que avaliam a produção e a implementação da política. Então, este é um setor da sociedade que conseguiu garantir para si o controle de uma política que é do Estado e que, portanto, deveria ser da sociedade como um todo.

Atualmente, a política de C\&T passa a se legitimar pelo discurso da inovação fomentando o desenvolvimento econômico por meio da centralidade do papel da empresa que acaba sendo a responsável pela inovação. Segundo essa linha de pensamento, a política de C\&T teria que fomentar a inovação empresarial para que a empresa levasse a produção de conhecimento até a sociedade. De acordo com esse discurso, a empresa é o locus da inovação. Então, ela seria responsável por levar até a sociedade produtos de tecnologia mais avançada, reconstruir o conhecimento na forma de produtos, processos que vão ser comercializados, ou seja, direcionados ao mercado e, portanto, ao consumo.

Esse modelo da cadeia linear no campo da inovação tecnológica convencional "supõe que, à pesquisa científica segue-se a tecnológica, e que a tecnologia traz o desenvolvimento econômico e depois o desenvolvimento social" (Baumgarten, 2006, p. 302). É considerando essa perspectiva que se pode relacionar o avanço ou atraso das sociedades quanto à sofisticação tecnológica que possuem e quanto ao seu uso, ou seja, se está ou não a serviço da humanidade e da justiça social. Assim sendo, "as tecnologias são construídas socialmente. Grupos de consumidores e interesses políticos e econômicos, entre outros, influenciam o conteúdo da tecnologia e sua forma final" (Baumgarten, 2006, p. 303).

Ao retomar o contexto de institucionalização da PCT no Brasil, identifica-se uma lacuna na relação entre ciência e sociedade, cabendo questionar: em que medida a produção do conhecimento tem atendido às demandas da sociedade? Como uma sociedade que ainda apresenta altos índices de desigualdade social pode avançar se não o fizer privilegiando o conjunto da so- 
ciedade? Qual articulação é necessária entre ciência, tecnologia, inovação e Estado de direito?

Com o início do governo de Luiz Inácio Lula da Silva, verifica-se que há uma priorização da temática da inclusão social, sendo demandadas das áreas estratégicas de governo, respostas voltadas ao desenvolvimento social. No campo do MCT, é sinal dessa priorização, a criação da Secretaria de Ciência e Tecnologia para Inclusão Social que tem no CNPq e na Finep as duas grandes agências implementadoras da política. Entretanto, a criação dessas estruturas não assegura a destinação de recursos específicos para esse campo, pois esses ainda são disputados com outras áreas, portanto, são limitados.

Em 2007, foi lançado o Plano Nacional de Ciência, Tecnologia e Inovação que possui quatro prioridades: infraestrutura de pesquisa, áreas estratégicas, inovação empresarial e desenvolvimento social. Contudo, a previsão de recursos para a prioridade do desenvolvimento social é de apenas 4\%. É preciso reconhecer os avanços do MCT que, ao instituir, por exemplo, o Programa de Tecnologias Sustentáveis (PTS), sinaliza a criação de um instrumento importante de política pública, abrindo caminhos para o processo de inclusão e desenvolvimento social, regional e local, por meio de iniciativas que promovem e incentivam a apropriação do conhecimento técnico-científico. Entretanto, muito temos que avançar na ampliação dos recursos e, fundamentalmente, na democratização do acesso para que a apropriação do conhecimento seja um direito de todo cidadão e então se possa fazer uso de um conhecimento que atenda as demandas da sociedade contribuindo com o enfrentamento da desigualdade social brasileira.

Entre as iniciativas no campo da política nacional de assistência social e a de segurança alimentar no Brasil destaca-se o MCT, ao instituir como objetivo de gestão a disseminação das TS. Com o objetivo de garantir aos moradores da área rural do semiárido brasileiro o acesso à água potável, o Ministério do Desenvolvimento Social e Combate à Fome (MDS) disponibiliza, no ano de 2010, recursos da ordem de $\mathrm{R} \$ 37$ milhões para parcerias com estados da região. Por meio de edital público, unidades da federação podem concorrer a uma seleção para a construção de cisternas de placas. ${ }^{4} \mathrm{O}$ apoio federal visa ampliar o

4. A cisterna é uma tecnologia popular para a captação de água da chuva e representa solução de acesso a recursos hídricos para a população rural dispersa do semiárido brasileiro. Construída com placas de 
acesso à água para o consumo humano por meio da construção de cisternas de placas para captação de água da chuva, acompanhada de capacitação para a convivência com o semiárido. O recurso será para o financiamento de despesas de capital, como a compra de materiais e o pagamento da mão de obra para a construção. Os beneficiários são famílias que não dispõem de acesso à fonte de água potável localizadas na zona rural do semiárido que possuem renda per capita familiar de até meio salário mínimo ou, no caso dos idosos, renda total da família de até três salários mínimos, devendo ser priorizadas as famílias que se enquadram nos critérios de elegibilidade do Programa Bolsa Família. Pode-se observar que esta iniciativa do MDS visa o acesso, o gerenciamento e a valorização da água como um direito essencial da vida e da cidadania, ampliando a compreensão e a prática da convivência sustentável e solidária com o ecossistema do Semiárido.

Também em destaque nessa luta social estão as organizações da sociedade civil, que têm deixado marcas no processo histórico do debate acerca das TS e do papel da ciência, tecnologia e inovação para a inclusão social, para o desenvolvimento sustentável e o enfrentamento da desigualdade social no Brasil. Um conjunto de ações é promovido, por meio das iniciativas da sociedade civil em territórios brasileiro, onde de forma sustentável desenvolvem tecnologias sociais que permitem a superação e o atendimento de necessidades sociais. Há aí a necessidade latente de reconhecimento do papel dessas organizações na produção de conhecimento e incidência na melhoria das condições de vida, porém não como algo a vir a ser, mas como parte de uma política pública que cria formas de financiamento e incentivos técnicos e educativos as suas ações dentro do sistema de ciência, tecnologia e inovação.

Assim, quatro questões são centrais na discussão acerca do modelo e padrão da política de ciência e tecnologia no país: os atores centrais na política voltada para o desenvolvimento social são a própria sociedade, e não os cientistas; o necessário reconhecimento do esgotamento da concepção de que o desenvolvimento social será uma consequência do desenvolvimento econômico; a insuficiência de recursos para viabilizar a prioridade do desenvolvimento social, presente no Plano Nacional de Ciência, Tecnologia e Inovação; a ausência de

cimento, permite armazenar 16 mil litros de água, o suficiente para o uso de uma família de cinco pessoas durante o longo período da seca que se estende por até oito meses. 
uma política de caráter público no âmbito da C\&T, ou seja, passível de controle social.

Sobre essa última questão, não há como negar os avanços na democracia participativa no cenário brasileiro, fundamentalmente a partir da Constituição de 1988 que faz referência sobre a participação da sociedade civil por meio de conselhos e que têm o papel de estabelecer um processo de codeliberação sobre as diversas políticas públicas, entre elas a saúde, a assistência social e as políticas de desenvolvimento rural. No contexto brasileiro, pode-se dizer sobre o controle social que este se

concretiza no processo de mobilização social de acordo com a capacidade da sociedade civil organizada de interferir na gestão pública. Isso se viabiliza de forma coletiva, através da apropriação de processos, participação na deliberação, fiscalização das ações estatais, avaliação e crítica, (re)orientando as ações e prioridades do Estado" (Pedrini, Adams e Silva, 2007, p. 226).

Sabemos que o caminho a percorrer para que se possa avançar na legitimação dos processos participativos e da construção da cidadania ativa na política de ciência e tecnologia no Brasil é longo, mas necessário. Alguns $\operatorname{estudos}^{5}$ apontam o quanto a maior "participação da sociedade nos espaços de controle social de políticas públicas na área social é bem-vista desde que não interfira nas políticas de investimento" (Pedrini, Adams e Silva, 2007, p. 231). Sob esta constatação pode-se imaginar o quão árdua é a tarefa de reverter a lógica dos processos participativos da sociedade civil na condução da PCT no país, uma vez que as rédeas da condução estão ainda sob grupos econômicos que exercem forte influência sobre o Estado. Em que pesem as conquistas democráticas no campo da política no cenário brasileiro, marcada pelo período de redemocratização, não foi possível alterar a lógica do inves-

5. Ainda que a reflexão deste artigo tenha como tema central as TS e sua defesa como política pública, compreender a importância do controle social e da participação ativa da cidadania brasileira no campo da C\&T é fundamental. "A construção de uma democracia participativa em todos os espaços da vida social deve levar em conta os limites colocados pela hegemonia das forças do capital [...] a resistência e a organização participativa podem fortalecer o movimento contra-hegemônico das forças emancipadoras da sociedade contra o determinismo" (Pedrini, Adams e Silva, 2007, p. 232). Sobre o controle social e os conselhos, sugerimos ver: Pedrini, Adams e Silva, 2007. 
timento econômico imposta pelos ideários neoliberais, o que resultou no crescimento da concentração de renda e, consequentemente, na desigualdade social.

Diante dessas questões, a defesa das TS como política pública se apresenta como uma estratégia promissora para superar os limites do atual modelo e padrão de C\&T no país, bem como a resposta mais sintonizada com as demandas da sociedade por um modelo de desenvolvimento social que tenha centralidade no processo de inclusão social e como atores principais a própria sociedade. Atualmente, as TS apresentam significativo avanço no país, seja pelas organizações que se instituíram na última década, com vistas à disseminação dos conceitos e práticas, seja pela capacidade de criação das mesmas, por meio das iniciativas populares e da sua reaplicação em todo o território nacional.

Considerando o exposto até aqui é preciso avançar na constituição das TS como política pública. No campo de atuação das políticas públicas, a participação do Estado, seja como regulador, seja como provedor ou garantidor de bens públicos como direito, é fundamental. Entretanto uma política pública não é só do Estado, pois para sua existência a sociedade também exerce papel ativo e decisivo, exigindo do Estado, atitudes positivas, ativas para transformar valores democráticos, de justiça social e de direitos em realidade. Assim sendo, a compreensão sobre políticas públicas nos remete a concepção de Estado que "não é um fenômeno dado, aistórico, neutro e pacífico, mas um conjunto de relações criado e recriado num processo histórico tenso e conflituoso em que grupos, classes ou frações de classe se confrontam e se digladiam em defesa de seus interesses particulares (Pereira, 2008, p. 26).

É dessa concepção que se pode afirmar que o Estado é uma arena de conflitos de interesses. Portanto, uma política pública se constrói a partir dessas disputas, onde "confluem interesses de natureza contraditória advindos da presença dos diferentes atores, imprimindo múltiplas dimensões à problemática da intervenção estatal" (Baumgarten, 2008, p. 67). É então num terreno de disputas que as PCT se conformam, e é possível afirmar que essas políticas "perpassam o campo das necessidades sociais, articulando-se, também, às exigências do desenvolvimento capitalista e assumindo nos Estados centrais, um papel estruturante em conjunto com outras políticas responsáveis por áreas e setores infraestruturais" (Baumgarten, 2008, p. 67). 
A noção de política pública como uma forma de organização política que se pauta pelo interesse comum, da comunidade, da soberania popular, e não da soberania dos que governam, permite a participação da população nas tomadas de decisões sobre as políticas, bem como a alocação dos seus recursos. Desta forma, reconhecer no cenário atual do país as TS como política pública significa avançar na história da democratização do conhecimento, da ciência, da tecnologia e da inovação social, contribuindo com a efetiva concretização do direito do ser humano à autonomia, à informação, à convivência familiar e comunitária saudável, ao desenvolvimento intelectual, às oportunidades de participação e ao usufruto do progresso sustentável (Perei$\mathrm{ra}, 2008)$.

Reconhecer que o desenvolvimento social apresenta particularidades distintas daquelas relacionadas ao desenvolvimento econômico é fundamental, pois se a lógica do segundo é a produtividade e a lucratividade, a lógica do primeiro é a garantia dos direitos sociais, portanto, permeada pelos valores da igualdade e justiça social. É desse contexto que emerge a necessidade de garantir a participação da sociedade civil organizada nos espaços de formulação, implementação e avaliação da política de ciência e tecnologia, por meio da institucionalização das tecnologias sociais como política pública, constituindo, para tanto, o plano, o fundo e o Conselho de Ciência e Tecnologia. Para tanto será preciso fortalecer e até mesmo criar, os mecanismos de controle social das políticas públicas de ciência e tecnologia, a exemplo das políticas de assistência social, educação e saúde, legitimando e, em alguns estados, constituindo os Conselhos de Ciência e Tecnologia.

Assim, a ampliação dos recursos para a prioridade do desenvolvimento social e sustentável, submetendo-os aos mecanismos de controle social, poderá garantir a necessária transparência na gestão do fundo público na área. No momento histórico atual se desenha, no cenário brasileiro, uma importante luta social em que diferentes segmentos e atores sociais, sobretudo aqueles comprometidos com projetos societários que se contrapõem ao modelo excludente vigente, não têm poupado esforços para instituir a TS como política pública. $\mathrm{Na}$ esteira desse movimento está o convite e, por que não dizer, a demanda para que os assistentes sociais venham a compor o grupo de atores sociais que lutam pelas TS como política pública e pela sua reaplicação em todo o território nacional, dado o seu caráter inovador no campo social. 


\section{Reflexões finais: aproximando o Serviço Social do debate acerca das tecnologias sociais}

A trajetória do Serviço Social brasileiro tem sido marcada pelo compromisso ético-político com um projeto societário vinculado aos interesses da classe trabalhadora e iluminado teoricamente por uma perspectiva crítica em que os assistentes sociais têm como desafio, no seu trabalho profissional cotidiano, "apreender e revelar os novos meandros da questão social" (Iamamoto, 2002, p. 31). A articulação do Serviço Social e a questão social se dão em virtude de essa última ser considerada o eixo que articula "a gênese das sequelas inerentes ao modo de produção/reprodução do capitalismo, das mudanças no mundo do trabalho, das suas manifestações e expressões concretas na realidade social, as estratégias de seu enfrentamento articuladas pelas classes sociais e o Estado" (Maciel, 2006, p. 13).

A questão social não é considerada como algo estático, isolado ou como um problema natural de determinada sociedade, mas sim resultado de um processo histórico de conflito na relação capital e trabalho, que vem adquirindo novas conformações nos últimos tempos, por força de mudanças profundas na reestruturação produtiva, na forma de gestão do Estado, nas políticas sociais e pelo “chamado 'princípio de exclusão', que se concretiza tanto da parte dos excluídos do processo produtivo do trabalho salariado, quanto da parte dos excluídos pela origem étnica, pela identidade cultural e pelas relações de gênero" (Wanderley e Belfiore-Wanderley, 2004, p. 59).

As múltiplas expressões da questão social, caracterizadas pela situações de vulnerabilidade social, pelos desemprego estrutural, pela violação do direitos, pela falta de saneamento básico, pela violência urbana e a familiar, entre outras, vivenciadas pela população brasileira, evidenciam o quanto a problematização e a compreensão das configurações atuais fazem parte dos objetivos do processo de trabalho profissional. Assim, captar a dinâmica da realidade social significa reconhecer os movimentos de resistência e superação por parte da classe trabalhadora das adversidades impostas pelos ideários neoliberais.

As iniciativas de TS se constituem em uma das mais profícuas alternativas de enfrentamento das expressões da questão social, por se tratar de experiências constituídas por meio das iniciativas comunitárias locais, pelo saber popular em articulação com os saberes acadêmicos, por processos participativos e demo- 
cráticos e, fundamentalmente, pela capacidade em romper com a lógica linear de produção do conhecimento científico, já que a necessidade/demanda social é o fim primeiro da produção do conhecimento, ou seja, o conhecimento é colocado a serviço do desenvolvimento social e a tecnologia é uma mediação para a garantia dos direitos sociais, e não um meio para ampliar a competitividade do país na oferta de novos bens para o consumo.

Além disso, são reveladoras da capacidade da sociedade em se organizar em função dos interesses da comunidade, partindo, muitas vezes, da identificação do capital já existente na comunidade e que passa a ser potencializado para benefício da coletividade. Em alguns casos, esse processo de organização vem acompanhado do trabalho, em parceria, de técnicos e pesquisadores, mas é importante destacar que esse acompanhamento não é uma condição sine qua non para que se constituam as TS. Na prática, o que se verifica é que muitas experiências de TS necessitam de uma sistematização para que possam ser reaplicadas em outras comunidades e, com isso, contribuam com o incremento de alternativas para a superação das condições adversas em que se encontra parcela significativa da população brasileira.

Com base nessas considerações, questionamos: Quais são os assistentes sociais que estão atuando junto às comunidades que vêm desenvolvendo TS? Quais são os pesquisadores da área que estão desenvolvendo pesquisas que amparam tais iniciativas? Quais são os profissionais que estão compondo as redes que apoiam a sistematização e a reaplicação das TS?

Tendo como balizador a nossa experiência no campo das TS, como profissionais que atuam na articulação da RTS no estado do Rio Grande do Sul, este é um campo fértil para o trabalho profissional, tendo em vista a ampla gama de possibilidades que a utilização das TS permite no estabelecimento de interfaces entre as políticas sociais, assim como na histórica expertise da profissão em trabalhar com os processos organizativos e, mais recentemente, na sistematização de conhecimentos oriundos das experiências populares. Igualmente, as TS se constituem em uma temática que, necessariamente, precisa ser incorporada na agenda das instituições formadoras e de pesquisa, pois esse movimento tende a crescer ainda mais nos próximos anos e, com ele, a necessidade de profissionais qualificados.

Este é um movimento promissor que nasce das comunidades, vem se ampliando nas redes que apoiam e disseminam as TS e se potencializa como 
uma futura política pública. Portanto, é uma demanda que a profissão está desafiada a compreender e a intervir. Com uma vantagem: o movimento histórico das TS no Brasil e os atores que a sustentam apresentam uma grande proximidade com os princípios e valores que norteiam o projeto político do Serviço Social. Tal proximidade, se coadunada com a intervenção dos assistentes sociais pode vir a qualificar ainda mais as TS, tornando-as um exemplo concreto de inovação social.

Artigo recebido em abr./2010 - Aprovado em dez./2010

\section{Referências bibliográficas}

BRASIL - Ministério do Desenvolvimento Social e Combate a Fome - MDS. MDS disponibiliza $R \$ 37$ milhões para cisternas no Semiárido. Disponível em: $<$ http://www. mds.gov.br/editais>. Acesso em: 2 mar. 2010.

BAUMGARTEN, Maíra. Tecnologia. In: CATTANI, Antonio; HOLZMANN, Lorena. Dicionário de trabalho e tecnologia. Porto Alegre: Ed. UFRGS, 2006. p. 288-292.

. Conhecimento e sustentabilidade: políticas de ciência, tecnologia e inovação no Brasil contemporâneo. Porto Alegre: Ed. UFRGS/Ed. Sulina, 2008.

DAGNINO, Renato Peixoto. Tecnologias sociais: ferramenta para construir outra sociedade. Campinas: Unicamp, 2009.

; BRANDÃO, Flávio; NOVAES, Henrique. Sobre o marco analítico-conceitual da tecnologia social. In: MELLO, Claiton (Orgs.). Tecnologia social: uma estratégia para o desenvolvimento. Rio de Janeiro: Fundação Banco do Brasil, 2004. p. 15-64.

FONSECA, Rodrigo Rodrigues. Política cientifica e tecnológica para o desenvolvimento social: uma análise do caso brasileiro. Tese (Doutorado) - Unicamp, Campinas, 2009.

FUNDAÇÃO BANCO DO BRASIL - FBB. Produção Agroecológica Integrada e Sustentável - PAIS. Cartilha Mais Alimento, Trabalho e Renda no Campo: saiba como produzir alimentos saudáveis e preservar o meio ambiente, 2008. Disponível em: $<\mathrm{http}: / /$ www.fbb.org.br/upload/noticia/documentos/1211316896453.pdf>. Acesso em: 21 nov. 2010.

IAMAMOTO, Marilda. Em tempo de capital fetiche: capital financeiro, trabalho e questão social. São Paulo: Cortez, 2007. 
IAMAMOTO, Marilda. O Serviço Social na contemporaneidade: trabalho e formação profissional. São Paulo: Cortez, 2002.

INSTITUTO DE PESQUISA ECONÔMICA APLICADA - IPEA. Crescimento e pobreza. Disponível em: <http://www.ipea.gov.br>. Acesso em: 22 fev. 2010.

INSTITUTO DE TECNOLOGIA SOCIAL - ITS. Declaração das ONGs: ciência e tecnologia com inclusão social. 2005. Disponível em: <http://www.itsbrasil.org.br>. Acesso em: 2 mar. 2010.

. Caderno Tecnologia Social - Conhecimento e Cidadania 1, fev. 2007. Disponível em: <http://www.itsbrasil.org.br>. Acesso em: 22 fev. 2010.

MACIEL, Ana Lúcia Suárez. Universidade em crise: uma travessia necessária para formação em Serviço Social. Tese (Doutorado) — PUC-RS, Porto Alegre, 2006.

; FERNANDES, Rosa Maria Castilhos. Documento: subsídios ao debate acerca das tecnologias sociais na $4^{\mathrm{a}}$ Conferência Nacional de Ciência, Tecnologia e Inovação (CNCTI). Porto Alegre: Fórum Social Mundial, jan. 2010.

NOVAES, Henrique; DIAS, Rafael. Contribuições ao marco-analítico conceitual da tecnologia social. In: DAGNINO, Renato Peixoto. Tecnologias sociais: ferramenta para construir outra sociedade. Campinas: Unicamp, 2009. p. 17-53.

PEDRINI, Dalila Maria; ADAMS Telmo; SILVA, Vini Rabassa (Orgs.). Controle social de políticas públicas: caminhos, descobertas e desafios. São Paulo: Paulus, 2007.

PEREIRA, Potyara. Estado, regulação social e controle democrático. In: BRAVO, M. Inês e PEREIRA, Potyara. Política social e democracia. 2. ed. São Paulo: Cortez, 2000. p. 25-42.

. Discussões conceituais sobre política social como política pública e direito de cidadania. In: BOSCHETTI, I.; BEHRING, E.; SANTOS, S.; MIOTO, R. (Orgs.). Política social no capitalismo: tendências contemporâneas. São Paulo: Cortez, 2008. p. 87-108.

REDE DE TECNOLOGIA SOCIAL — RTS. Disponível em: <http://www.rts.org.br>. Acesso em: 24 fev. 2010.

. Tecnologia social: conceito. Disponível em: <http://www.rts.org.br/rts/tecnologia-social/tecnologia-social>. Acesso em: 19 set. 2009.

WANDERLEY, Luis Eduardo; BELFIORE-WANDERLEY, Mariangela. CASTEL, Robert. Desigualdade e a questão social. São Paulo: EDUC, 2004. 